\title{
ANALISIS PENGARUH MERGER DAN AKUISISI TERHADAP KINERJA KEUANGAN DAN ABNORMAL RETURN PADA PERUSAHAAN DI BURSA EFEK INDONESIA TAHUN 2014-2018
}

\author{
Sylvi Liani Dewi \\ Program Studi Magister Manajemen Universitas Tarumanagara \\ sylvi.117182037@stu.untar.ac.id \\ Indra Widjaja \\ Program Studi Magister Manajemen Universitas Tarumanagara
}

Masuk : 25-05-2020, revisi : 25-06-2020 diterima untuk diterbitkan : 26-06-2020

\begin{abstract}
This study aims to examine the difference in firm performances and abnormal returns before and after the merger and acquisition in the companies listed on the Indonesian Stock Exchange in the year 2014 to 2018. The data observation period is 1 year before the merger dan acquisition and 2 years after merger and acquisition. The analysis technique used is the Wilcoxon Signed Rank Test for ratio performance and Paired Sample T-test for abnormal return. The results of the testing of the hypothesis show that period 1 year before M\&A and comparison comparison 2 years after M\&A shows there is no significant difference in company financial performance before and after merger and acquisition. Hypothesis for Abnormal return, there is no difference before and after merger and acquisition.
\end{abstract}

Abstrak : Penelitian ini bertujuan untuk menguji perbedaan kinerja perusahaan dan abnormal return sebelum dan sesudah merger dan akuisisi pada perusahaan yang terdaftar di Bursa Efek pada tahun 2014 hingga 2018. Periode observasi data adalah 1 tahun sebelum merger dan akuisisi dan $1 \& 2$ tahun sesudah merger dan akuisisi. Metode analisa data yang digunakan adalah Wilcoxon Signed Rank Test dan Paired Sample T-Test untuk abnormal return. Hasil pengujian hipotesis menunjukkan bahwa periode 1 tahun sebelum M\&A dan perbandingan 2 tahun setelah M\&A menunjukkan tidak ada perbedaan signifikan dalam kinerja keuangan perusahaan sebelum dan sesudah merger dan akuisisi. Hipotesis untuk Abnormal return, tidak ada perbedaan sebelum dan sesudah merger dan akuisisi.

Keywords : Acquisition, Merger, Financial Performance, Financial Ratio, Abnormal Returns

\section{PENDAHULUAN}

Perubahan signifikan dalam lingkungan bisnis seperti globalisasi telah menciptakan persaingan yang sangat ketat. Salah satu strategi perusahaan untuk bertahan dan unggul dari persaingan usaha adalah dengan melakukan ekspansi usaha. Menurut (Johan, 2018) salah satu cara ekspansi usaha yaitu melalui penggabungan usaha antara dua perusahaan atau lebih, yang biasa disebut Merger dan Akuisisi (M\&A). Tujuan dilakukannya M\&A untuk mendapatkan sinergi atau nilai tambah (Olang \& Akenga, 2017). Diharapkan melalui sinergi yang diberikan M\&A dapat meningkatkan kinerja keuangan (Jallow et al., 2017). Dalam pengukuran kinerja keuangan agar dapat meningkat, salah satu tolak ukurnya adalah dengan rasio keuangan Sedangkan respon pasar terkait informasi dalam pengumuman merger dan akuisisi ditunjukan dari perubahan harga saham perusahaan (Tarigan, 2018). Namun kinerja perusahaan setelah M\&A memperoleh hasil yang berbeda - beda, sehingga penelitian ini bertujuan untuk mengetahui ada tidaknya perbedaan kinerja keuangan perusahaan sebelum dan setelah M\&A dan juga perbedaan rata-rata abnormal return sebelum dan setelah M\&A. 


\section{TINJAUAN TEORITIS}

Teori sinyal (signaling theory) sangat berkaitan dengan informasi yang dijadikan sinyal bagi para investor (Wahyuni et al., 2018). Signaling Theory atau teori sinyal menurut Brigham.et al, 1997 dalam Prasetyo \&Akhmadi (2018) disebutkan bahwa informasi dari emiten dapat direspon berbeda oleh investor (positif atau negatif), yang akan mempengaruhi fluktuasi harga pasar saham. Salah satu peristiwa positif yang diyakinin memberikan sinyal positif, agar investor mau berinvestasi adalah pengumuman akuisisi yang diberikan oleh manajamen terhadap pasar (Wirama \& Larasati, 2018). Jika pengumuman mengandung informasi, maka diharapkan pasar akan bereaksi pada waktu pengumuman dan ditunjukkan dengan adanya perubahan harga saham dari perusahaan tersebut. Reaksi ini dapat diukur dengan menggunakan return sebagai nilai perubahan harga atau dengan menggunakan abnormal returns (Tarigan et al.,2018). Abnormal return adalah selisih antara tingkat keuntungan yang sebenarnya dengan tingkat keuntungan yang diharapkan (Hasanah \& Oktaviani, 2017). Abnormal return akan terjadi apabila pasar bereaksi terhadap pengumuman M\&A yang mempunyai informasi dalam pasar modal dan terjadi tingkat pengembalian sehingga memperoleh keuntungan diatas normal (Sumantri \& Agustianti, 2017).

Synergy theory sendiri pertama kali dikemukakan oleh Gunther 1955, dimana disebutkan bahwa merger dan akuisisi terjadi secara luas karena merger dan akuisisi menghasilkan suatu "sinergi" antara pengakuisisi dan target. Sinergi tersebut diharapkan akan meningkatkan nilai perusahaan. (Omotayo, 2019). Synergy Theory menjelaskan bahwa dua perusahaan akan memperoleh keuntungan lebih besar ketika keduanya melakukan penggabungan dibandingkan sendiri. (Panayides et al.,2018).

Merger adalah penggabungan dua (atau lebih) perusahaan dengan mempertahankan salah satu perusahaan (Taringan et al.,2018). Menurut PSAK 22 akuisisi adalah suatu penggabungan usaha dimana salah satu perusahaan, yaitu pengakuisisi (aquirer) memperoleh kendali atas aset neto dan operasi perusahaan yang diakuisisi (aquiree), dengan memberikan aset tertentu, mengakui suatu kewajiban atau mengeluarkan saham (Ghozali, 2019).

Kinerja keuangan suatu perusahaan merupakan salah satu dasar penilaian kondisi keuangan perusahaan (Sumantri\&Agustianti, 2017), dimana rasio merupakan alat analisis yang digunakan untuk mengetahui kondisi keuangan suatu perusahaan dan meninjau kinerja manajemen dalam suatu periode tertentu (Hasanah\&Oktaviani,2017). Menurut Ghozali (2019) jika perusahaan bergabung sehingga bertambah besar ditambah dengan sinergi yang dihasilkan dari gabungan aktivitas-aktivitas yang simultan maka laba perusahaan juga semakin meningkat.

Dalam rangka meneliti pengaruh merger dan akuisisi terhadap kinerja keuangan dan abnormal return pada perusahaan, maka dapat digambarkan model penelitian sebagai berikut (Gambar 1) :

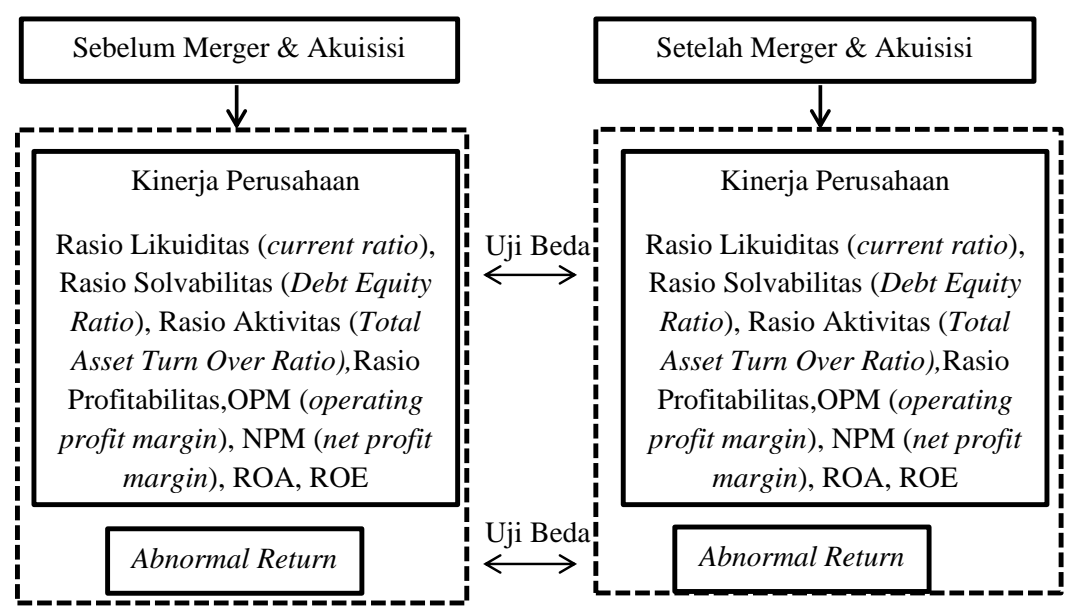

Gambar 1 Model Penelitian 
Berdasarkan model penelitian diatas, maka dirumuskan hipotesis sebagai berikut:

H1: Current ratio berbeda antara sebelum dan sesudah M\&A

H2: Debt equity ratio berbeda antara sebelum dan sesudah M\&A

H3: Total Asset turnover ratio berbeda antara sebelum dan sesudah M\&A

H4: Operating profit margin berbeda antara sebelum dan sesudah M\&A

H5: Net profit margin berbeda antara sebelum dan sesudah M\&A

H6: Return on Asset berbeda antara sebelum dan sesudah M\&A

H7: Return on equity berbeda antara sebelum dan sesudah M\&A

H8: Abnormal return berbeda antara sebelum dan sesudah pengumuman M\&A

\section{METODE PENELITIAN}

Metode pengambilan sampel yang digunakan adalah metode Purposive Sampling dengan kriteria yang digunakan untuk memilih sampel adalah tahun merger dan akuisisi, kelengkapan data, dan perusahaan harus tercatat di Bursa Efek Indonesia. Sampel yang digunakan adalah data sekunder yang berupa laporan keuangan tahunan yang diperoleh dari Bursa Efek Indonesia atau website perusahaan yang terkait. Pengujian dilakukan menggunakan software SPSS 25 .

Penelitian data bersifat kuantitatif, kemudian data akan dianalisa dengan analisis statistik deskriptif lalu kemudian akan dilakukan pengujian uji normalitas data dengan menggunakan uji kolmogorov-smirnov/ Shapiro Wilk. Kemudian tahap selanjutnya dilakukan pengujian hipotesis untuk masing-masing variabel penelitian dengan menggunakan uji analisis Paired Sample T Test apabila data berdistribusi normal atau metode analisis Wilcoxon Signed Rank Test apabila data berdistribusi tidak normal.

Tabel 1

Pengukuran Variabel Penelitian

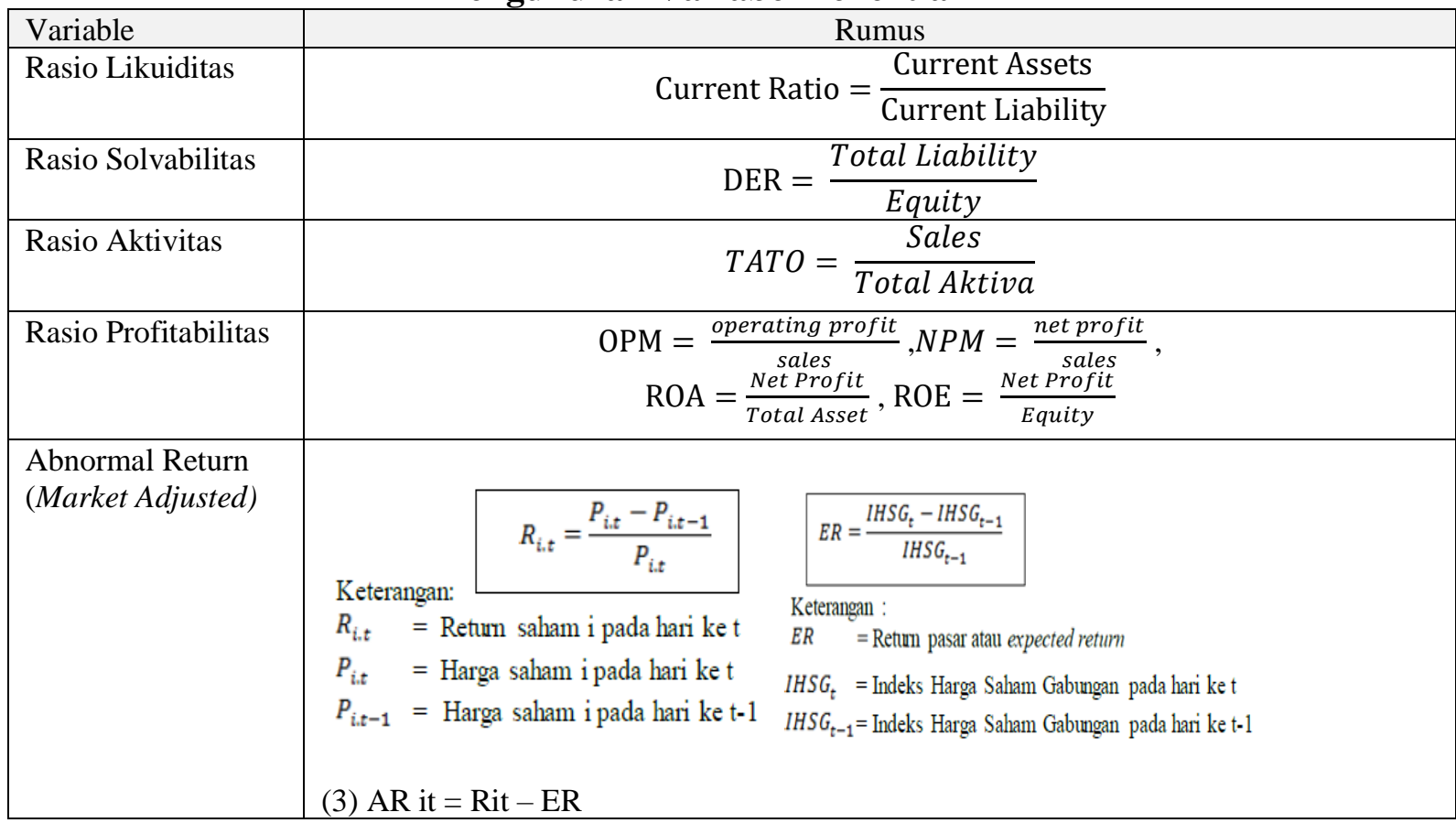

\section{ANALISIS DAN PEMBAHASAN PENELITIAN}

Berdasarkan hasil analisis yang dilakukan menunjukan statistik deskriptif dimana nilai standar deviasi lebih tinggi dari rata-rata bearti data memiliki sifat yang lebih bervariasi. Sebaliknya, jika nilai standar deviasi menunjukan nilai yang lebih kecil dari rata-rata maka hal ini menandakan bahwa data memiliki nilai variasi yang kecil. Nilai maksimum mengindikasikan nilai terbesar dari data dalam variabel yang sama. Sedangkan nilai minimum mengindikasikan nilai terkecil dari data dalam variabel yang sama. 
Tabel 2

Statistik Deskriptif Ratio Keuangan Sebelum dan Setelah Merger dan Akuisisi

\begin{tabular}{|c|c|c|c|c|c|c|c|c|c|c|c|c|c|}
\hline Var. & $\mathrm{N}$ & $\begin{array}{c}\text { Mean } \\
\text { Year - } \\
1 \\
\end{array}$ & $\begin{array}{c}\text { Std. } \\
\text { Dev. } \\
\text { Year - } \\
1 \\
\end{array}$ & $\begin{array}{c}\text { Min } \\
\text { Year } \\
-1 \\
\end{array}$ & $\begin{array}{c}\text { Max } \\
\text { Year } \\
-1 \\
\end{array}$ & $\begin{array}{c}\text { Mean } \\
\text { Year } \\
+1 \\
\end{array}$ & $\begin{array}{c}\text { Std. } \\
\text { Dev. } \\
\text { Year } \\
+1\end{array}$ & $\begin{array}{c}\text { Min } \\
\text { Year } \\
+1 \\
\end{array}$ & $\begin{array}{c}\text { Max } \\
\text { Year } \\
+1 \\
\end{array}$ & $\begin{array}{c}\text { Mean } \\
\text { Year } \\
+2 \\
\end{array}$ & $\begin{array}{c}\text { Std. } \\
\text { Dev. } \\
\text { Year } \\
+2 \\
\end{array}$ & $\begin{array}{c}\text { Min } \\
\text { Year } \\
+2 \\
\end{array}$ & $\begin{array}{c}\text { Max } \\
\text { Year +2 }\end{array}$ \\
\hline $\mathrm{CR}$ & 20 & 14.08 & 54.87 & 0.46 & 247.13 & 1.75 & 1.52 & 0.24 & 6.20 & 2.39 & 3.34 & 0.13 & 15.62 \\
\hline DER & 20 & 1.32 & 1.29 & 0.00 & 6.30 & 1.38 & 0.99 & 0.20 & 3.70 & 1.28 & 0.77 & 0.20 & 3.09 \\
\hline TATO & 20 & 0.70 & 0.60 & 0.00 & 2.56 & 0.70 & 0.67 & 0.01 & 2.73 & 0.66 & 0.65 & 0.01 & 2.74 \\
\hline OPM & 20 & 8.65 & 37.29 & 0.08 & 167.06 & 0.42 & 0.76 & -0.10 & 3.55 & 0.36 & 0.54 & -0.23 & 2.50 \\
\hline NPM & 20 & 9.12 & 40.06 & 0.00 & 179.33 & 0.18 & 0.74 & -1.21 & 3.03 & 0.13 & 0.61 & -1.52 & 2.18 \\
\hline ROE & 20 & 0.20 & 0.22 & 0.01 & 0.99 & 0.09 & 0.11 & -0.21 & 0.28 & 0.12 & 0.13 & -0.28 & 0.28 \\
\hline ROA & 20 & 0.08 & 0.06 & 0.00 & 0.26 & 0.04 & 0.06 & -0.12 & 0.15 & 0.06 & 0.07 & -0.13 & 0.18 \\
\hline
\end{tabular}

\section{Tabel 3}

Statistik Deskriptif Abnormal Return 20 Hari

Sebelum dan 20 Hari Setelah Merger dan Akuisisi

\begin{tabular}{|lr|r|r|r|r|}
\hline & N & Mean & Std. Deviation & \multicolumn{1}{c|}{ Minimum } & Maximum \\
\hline D-20 Sebelum M\&A & 20 & 0.0017 & 0.00854 & -0.01 & 0.02 \\
D+20 Setelah M\&A & 20 & 0.0024 & 0.0198 & -0.04 & 0.06 \\
\hline
\end{tabular}

\section{Uji Normalitas}

Berdasarkan hasil uji normalitas ratio dibawah, sebagian besar sampel yang berdistribusi tidak normal adalah sebanyak $86 \%$ (probabilitas < taraf signifikan $\alpha=0,05$ ). sedangkan yang berdistribusi normal berjumlah $14 \%$ (probabilitas $>$ taraf signifikan $\alpha=0,05$ ). Maka dari itu data rasio keuangan tersebut dapat disimpulkan berdistribusi tidak normal. Oleh karena itu uji statistik yang akan dipakai untuk uji hipotesis rasio keuangan adalah uji non parametrik, yaitu uji Wilcoxon Signed Rank Test.

Tabel 4

Hasil Uji Normalitas Ratio Sebelum dan Setelah Merger dan Akuisisi

\begin{tabular}{|l|r|r|r|}
\hline Variable & Year -1 & Year +1 & Year+2 \\
\hline CR & 0.0000 & 0.0000 & 0.0000 \\
DER & 0.0000 & 0.0050 & 0.0313 \\
TATO & 0.0070 & 0.0040 & 0.0020 \\
OPM & 0.0000 & 0.0000 & 0.0000 \\
NPM & 0.0000 & 0.0000 & 0.0000 \\
ROE & 0.0000 & 0.4570 & 0.0271 \\
ROA & 0.0420 & 0.2520 & 0.1791 \\
\hline
\end{tabular}

\section{Tabel 5}

Hasil Uji Normalitas Abnormal Return Sebelum dan Setelah Merger dan Akuisisi

\begin{tabular}{|l|r|r|}
\hline Variable & D-20 Sebelum M\&A & 20 Hari Setelah M\&A \\
\hline Abnormal Return & 0.476 & 0.064 \\
\hline
\end{tabular}

Sedangkan hasil uji normalitas menunjukan data berdistribusi normal. Uji parametrik yang digunakan untuk pengujian hipotesis yaitu Paired Sample T-Test.

\section{Uji Hipotesis}

\section{Tabel 6}

Hasil Uji Hipotesis Wilcoxon Signed Rank Test Rasio

1 Tahun Sebelum dan 1 Tahun Setelah Merger Dan Akuisisi

\begin{tabular}{|l|c|r|l|}
\hline \multicolumn{1}{|c|}{ Variable } & Sig Year +1 & A & \multicolumn{1}{|c|}{ Simpulan Year + 1 } \\
\hline CR & 0.38 & 0.05 & H1 ditolak \\
\cline { 2 - 5 } DER & 0.39 & 0.05 & H2 ditolak \\
\cline { 2 - 5 } TATO & 0.965 & 0.05 & H3 ditolak \\
OPM & 0.467 & 0.05 & H4 ditolak \\
ROE & 0.016 & 0.05 & H5 diterima \\
ROA & 0.017 & 0.05 & H6 diterima \\
\hline \multicolumn{2}{|c|}{ Hasil data menunjukan bahwa variable rasio kinerja keuangan untuk CR, } \\
\cline { 3 - 5 }
\end{tabular}

DER,TATO,OPM hipotesis ditolak (sig $>0,05$ ), sedangkan untuk variable rasio kinerja keuangan NPM, ROE, dan ROA hipotesis diterima (Sig <0,05). 
Tabel 7

Hasil Uji Hipotesis Wilcoxon Signed Rank Test Rasio

1 Tahun Sebelum dan 2 Tahun Setelah Merger dan Akuisisi

\begin{tabular}{|l|c|c|c|}
\hline \multicolumn{1}{|c|}{ Variable } & Sig Year +2 & A & Simpulan Year +2 \\
\hline CR & 0.542 & 0.05 & H1 ditolak \\
\cline { 2 - 4 } DER & 0.709 & 0.05 & H2 ditolak \\
\cline { 2 - 4 } TATO & 0.295 & 0.05 & H3 ditolak \\
\cline { 2 - 4 } OPM & 0.130 & 0.05 & H4 ditolak \\
RPM & 0.285 & 0.05 & H5 ditolak \\
\hline ROE & 0.459 & 0.05 & H6 ditolak \\
\hline
\end{tabular}

Hasil data menunjukan bahwa untuk semua variable ratio keuangan memperoleh signifikansi $>0,05$, yang berarti hipotesis ditolak.

Tabel 8

Hasil Uji Hipotesis Paired Samples T-Test Abnormal Return

20 Hari Sebelum dan Setelah Merger dan Akuisisi

\begin{tabular}{|c|c|c|c|c|c|c|c|c|}
\hline \multicolumn{9}{|c|}{ Paired Samples Test } \\
\hline & \multicolumn{5}{|c|}{ Paired Differences } & \multirow[b]{3}{*}{$\mathrm{T}$} & \multirow[b]{3}{*}{$\mathrm{df}$} & \multirow{3}{*}{$\begin{array}{l}\text { Sig. }(2- \\
\text { tailed })\end{array}$} \\
\hline & \multirow[b]{2}{*}{ Mean } & \multirow[b]{2}{*}{ Std. Dev. } & \multirow{2}{*}{$\begin{array}{l}\text { Std. Error } \\
\text { Mean }\end{array}$} & \multicolumn{2}{|c|}{$\begin{array}{l}95 \% \text { Confidence Interval } \\
\text { of the Difference }\end{array}$} & & & \\
\hline & & & & Lower & Upper & & & \\
\hline $\begin{array}{l}\text { D-20 M\&A - } \\
\text { D+20 M\&A }\end{array}$ & -0.00073 & 0.02098 & 0.00469 & -0.01055 & 0.00909 & -0.156 & 19 & 0.878 \\
\hline
\end{tabular}

Berdasarkan data maka dapat disimpulkan bahwa tidak terdapat pengaruh/ tidak terdapat perbedaan untuk Abnormal Return, yang berarti hipotesis 8 ditolak. (Sig 0,87>0,05)

\section{KESIMPULAN DAN SARAN}

Jadi dapat disimpulkan bahwa dalam penelitian ini tidak terdapat perbedaan rasio keuangan antara sebelum merger akuisi dan setelah merger akuisisi. Hal tersebut menimbulkan dugaan bahwa sinergi yang terjadi setelah merger dan akuisisi belum tercapai, dikarenakan faktor lain seperti penyelamatan perusahaan dari kebangkrutan, motif pribadi atau alasan lain yang berpengaruh terhadap kinerja keuangan perusahaan. Salah satu alasan menyebutkan ketidak cocokan budaya organisasi menyebabkan tidak terdapat perbedaan kinerja keuangan perusahaan (Tarba et al., 2019). Hasil pengujian paired samples $t$ - test terhadap abnormal return menunjukkan bahwa tidak terdapat perbedaan abnormal return yang signifikan pada pengumuman sebelum dan sesudah merger dan akuisisi. Hal ini menunjukkan bahwa selama periode hasil pengumuman merger dan akuisisi terhadap saham perusahaan baik sebelum dan sesudah merger akuisisi tidak memiliki perbedaan yang signifikan seperti yang disebutkan dalam signaling theory, alasan tidak ada respon terhadap pasar karena beberapa faktor, seperti pengumuman merger dan akuisisi bukan lagi peristiwa yang mengejutkan atau normal sehingga ekspektasi pasar sebelum dan sesudah pengumuman tidak jauh berbeda, kemudian informasi tentang merger dan akuisisi dimasukkan dalam agenda Rapat Umum Pemegang Saham (RUPS) yang mengakibatkan kebocoran informasi dan juga kurangnya saham aktif yang diperdagangkan di bursa. Hal ini menyebabkan pengembalian aktual tidak berubah dengan ekspestasi return tidak jauh berberda (Bucdadi et al., 2018).

Saran yang dapat diberikan agar penelitian selanjutnya dapat memperpanjang periode pengamatan dan memasukan pula aspek-aspek non ekonomis yang mungkin berpengaruh terhadap kinerja perusahaan, sehingga dapat diperoleh gambaran yang lebih lengkap mengenai kinerja perusahaan.

\section{DAFTAR PUSTAKA}

Akhmadi \& Prasetyo. (2018). Profitabilitas, Rasio Solvabilitas dan Harga Saham; Studi Empirik pada Perusahaan Subsektor Batubara yang Terdaftar di Bursa Efek Indonesia Periode 2010-2014. Jurnal Riset Akutansi Terpadu. 11 (1), April 2018, 61-7. 
Gozali \& Panggabean. (2019). Merger dan Akuisisi Dampaknya pada Likuiditas, Profitabilitas, Aktivitas, dan Solvabilitas; Bukti dari Bursa Efek Indonesia. Jurnal Ilmiah Ilmu Manajemen 2019, 13- 28. p-ISSN 2356-2005.

Hasanah \& Oktaviani. (2017). Analisis Kinerja Perusahaan dan Abnormal Return Saham Sebelum dan Sesudah Akuisisi. Jurnal Akuntansi, 4, 75-88. p-ISSN 2339-2436.

Jallow, et al. (2017). The Effect of Mergers \& Acquisitions on Financial Perfomance : Case Study of UK Companies. International Journal of Accounting \& Business Management, 5 (1), April 2017. ISSN: 2289-4519. DOI:24924/ijabm/2017.04/v5.iss1/74.92

Johan, Suwinto. (2018). Merger, Akuisisi, dan Restrukturisasi. Bogor : IPB Press

Olang \& Akenga. (2017). Effect of Mergers and Acquisitions on Financial Performance of Commercial Banks in Kenya. IOSR Journal of Business and Management (IOSR-JBM). e-ISSN: 2278-487X, p-ISSN: 2319-7668.

Omotayo. (2019). The Effect of Merger and Acquisition and Corporate Perfomance of The Nigerian Banking Industry. GSJ, 7 (11), Online : ISSN 2320-9186

Panayides, et al. (2018). The Reasons and Evaluations of Mergers and Acquisitions. Accounting and Finance Research, 7 (3). ISSN 1927-5986 E- ISSN 1927-5994

Sumantri \& Agustianti. (2017). Kinerja Keuangan, Abnormal Return Sebelum dan Setelah Pengumuman Merger. Jurnal Ekonomi dan Bisnis, 1, 73-93. p-ISSN: 2549-5658.

Tarigan. (2018). Analysis of Merger \& Acquisition Motives in Indonesian Listed Companies through Financial Performance. KINERJA, 22 (1). ISSN: 1411-0288

Wahyuni, et al. (2018). Analisis Komparatif Abnormal Return, Security Return Variability dan Trading Volume Activity Sebelum dan Sesudah Pilkada Serentak tahun 2018. JIMAT (Jurnal Ilmiah Mahasiswa Akuntansi) Universitas Pendidikan Ganesha, 9 (2). e-ISSN: $2614-1930$

Wirama \& Larasati. (2018). Respon Pasar Terhadap Pengumuman Akuisisi pada Perusahaan Pengakuisisi yang Terdaftar di BEI Tahun 2013-2017. E-Jurnal Akuntansi Universitas Udayana, 24. 507-530. ISSN: 2302-8556 